\title{
Investigations on Spectroscopic Properties of Manganese Ions in Sodium Lead Alumino Borate Glasses
}

Vijaya Babu karumuri ( $\square$ kamalavijay007@gmail.com )

Department of Physics, The Bapatla College of Arts \& Sciences, Bapatla-522101, A.P, India Madhuri Vema

Department of Physics, The Bapatla College of Arts \& Sciences, Bapatla-522101, A.P, India Suresh Boddu

Department of Physics, Acharya Nagarjuna University, N. Nagar-522501, A.P, India

\section{Research Article}

Keywords: Glasses, melt quenching, Infrared spectroscopy, Optical absorption, Electron paramagnetic resonance

Posted Date: August 11th, 2020

DOI: https://doi.org/10.21203/rs.3.rs-49497/v1

License: (a) (1) This work is licensed under a Creative Commons Attribution 4.0 International License. Read Full License 


\title{
Investigations on Spectroscopic Properties of Manganese Ions in Sodium Lead Alumino Borate Glasses
}

\author{
K. Vijaya Babu ${ }^{1 *}$, V. Madhuri ${ }^{2}$, B. Suresh ${ }^{3}$ \\ ${ }^{1}$ Department of Physics, The Bapatla College of Arts \& Sciences, Bapatla-522101, A.P, India \\ ${ }^{2}$ Department of Physics, The Bapatla College of Arts \& Sciences, Bapatla-522101, A.P, India \\ ${ }^{3}$ Department of Physics, Acharya Nagarjuna University, N. Nagar-522501, A.P, India
}

\begin{abstract}
:
Divalent manganese ions containing $20 \mathrm{Na}_{2} \mathrm{O}-15 \mathrm{PbO}-(5-\mathrm{x}) \mathrm{Al}_{2} \mathrm{O}_{3}-60 \mathrm{~B}_{2} \mathrm{O}_{3}: \mathrm{xMnO}_{2}$ (x ranging from 0 to $1 \mathrm{~mol} \%$ ) NPAB glasses are prepared by using melt quenching technique and are characterized by several spectroscopic techniques. Various physical parameters are calculated from the measured density values. Structural properties of $\mathrm{MnO}_{2}$ doped NPAB glasses are investigated by Powder XRD, EPR, UV-VIS absorption and FT-IR spectroscopic techniques. The amorphous nature of prepared glass samples are confirmed by $\mathrm{X}$ - ray diffraction spectra. EPR spectra of these glasses exhibited a well resolved six line hyperfine structure around $g=2.00$ is the characteristic nature of $\mathrm{Mn}$ (II) ions in distorted octahedral site symmetry. Optical absorption spectra of these glasses revealed a single broad band at $\square 21000 \mathrm{~cm}^{-1}$ which has been assigned to the transition ${ }^{6} \mathrm{~A}_{1 \mathrm{~g}}(\mathrm{~S}) \rightarrow{ }^{4} \mathrm{~T}_{1 \mathrm{~g}}(\mathrm{G})$ of $\mathrm{Mn}$ (II) ions. Optical band gap energies and Urbach energies are evaluated through the fundamental Ultra Violet absorption edges of the glasses. FT-IR spectra clearly exhibited different vibrational bands and assigned to borate groups and water molecules.
\end{abstract}

Key words: Glasses; melt quenching; Infrared spectroscopy; Optical absorption; Electron paramagnetic resonance 


\section{Introduction}

Lead alumino borate glasses find several applications in battery ceiling and other microelectronic packaging because of their properties like toughness, good strength, transparency, excellent corrosion resistance, high mechanical strength and low thermal expansion coefficients [1]. $\mathrm{B}_{2} \mathrm{O}_{3}$ acts as one of the most important glass formers and flux materials. Melts with compositions rich in $\mathrm{B}_{2} \mathrm{O}_{3}$ exhibit rather high viscosity and tend to formation of glasses [2]. Thus, borate glasses are enormously studied by different groups across the world due to its rich structural variation [3]. By the addition of various alkali modifiers, drastic structural changes occur in the borate structural units with the evolution of four coordinated boron and non bridging oxygen (NBO) ions in the glass network. Alkali-borate glasses have high mechanical strength, high electrical conductivity and relatively moistureresistant compared with pure borate glasses. Due to high electrical conductivity and ease in preparation of alkali-borate glasses, these are suggested as potential fast ion conducting solid electrolytes [4]. $\mathrm{Al}^{3+}$ ions are generally used as intermediate species [5]. When alkali-borate glasses consist of heaviest metal oxides such as $\mathrm{Al}_{2} \mathrm{O}_{3}$, are more promising for photonics and optoelectronics. Because of its attractive properties of high melting point, excellent resistivity, high wears resistance, high chemical durability, and low cost availability of raw materials, these glasses have been widely studied [6-9]. Addition of $\mathrm{PbO}$ to these glasses makes the materials more magnetically and electrically inert and also decrease the viscosity, increase the electrical resistivity and the ability to absorb $\mathrm{X}$-rays [10]. $\mathrm{PbO}$ in contrast with the conventional alkali metals, has ability to form stable glasses due to its dual role-one as modifier and the other as glass network former in both ionic [11] and covalent bonding [12, 13] with $\mathrm{PbO}_{4 / 2}$ pyramidal units connected in puckered layers [14]. The study of the glasses doped with transition metal ions and its physical properties is of considerable interest in the application point of view. The physical properties of these glasses can be enhanced by the addition of $\mathrm{PbO}$ to alkali alumino borate glasses. In recent years the study of glasses doped with transition metal ions have a wide range of applications in electronic, tunable solid state lasers, luminescent solar energy concentrators (LSCs) and fibre optic communication systems due to their memory and photo conducting properties [15]. 
Among various transition metal ions, $\mathrm{Mn}$ (II) is a distinctive luminescent ion with good potential applications. Mn-doped semiconductors are commonly used in magneto-optical, magneto-transport, spintronics, lasers, and infrared devices. Manganese-based thin film oxides can be utilized as electrode materials [16, 17], electrochemical capacitors [18, 19], rechargeable batteries, catalysts, sensors [20], magneto electronic devices [21]. Manganese is next to iron element, one of the most common impurities in glasses and it is used as coloring and decolouring agent [22]. In glass matrices, manganese ions exist in different valence states viz. $\mathrm{Mn}^{2+}$ and $\mathrm{Mn}^{3+}$, in borate and phosphate glasses with both tetrahedral and octahedral coordination [1]. The content of manganese oxide present in the glass matrix at a given temperature depends upon the quantitative properties of modifiers, glass formers, size of the ions in the glass structure, their field strength and mobility of the modifier cation, etc., [3].

Studies of the coordination, bonding characteristics and covalency state of transition metal ions in glasses are very useful to understand the structure of the glasses. Changes in the chemical composition of glass may change the local environment of the transition metal ion incorporated into the glass, leading to ligand field changes, which may be reflected in the optical absorption and EPR spectra. Structural properties of vitreous systems are frequently studied by means of EPR of Mn(II) ions used as paramagnetic probes [23]. To the best of our knowledge there is no previous literature reported on EPR and optical absorption studies of $\mathrm{Na}_{2} \mathrm{O}-\mathrm{PbO}$ $\mathrm{Al}_{2} \mathrm{O}_{3}-\mathrm{B}_{2} \mathrm{O}_{3}$ glasses doped with manganese ions.

Hence the present spectral investigations of manganese-bearing $\mathrm{Na} 2 \mathrm{O}-\mathrm{PbO}-\mathrm{Al}_{2} \mathrm{O}_{3}-\mathrm{B}_{2} \mathrm{O}_{3}$ (NPAB) glasses is undertaken in view of understanding the site symmetry of the metal ion, its oxidation state from the optical absorption and EPR spectroscopic studies. Structurally different borate units exist in this glass system are investigated by FT-IR spectroscopy.

\section{Experimental}

For the present study, a particular composition $20 \mathrm{Na}_{2} \mathrm{O}-15 \mathrm{PbO}-(5-\mathrm{x}) \mathrm{Al}_{2} \mathrm{O}_{3}-60 \mathrm{~B}_{2} \mathrm{O}_{3}$ : $\mathrm{xMnO}_{2}$ with six values of ' $\mathrm{x}$ ' ranging from 0 to 1 is taken. The detailed NPAB compositions of all the glass samples are listed in the Table 1.

\subsection{Glass Preparation}

The starting materials used in the present work are analar grade reagents sodium carbonate $\left(\mathrm{Na}_{2} \mathrm{CO}_{3}\right)$, lead oxide $(\mathrm{PbO})$, aluminum oxide $\left(\mathrm{Al}_{2} \mathrm{O}_{3}\right)$, boric acid $\left(\mathrm{H}_{3} \mathrm{BO}_{3}\right)$ and 
manganese oxide $\left(\mathrm{MnO}_{2}\right)$ with $99.9 \%$ purity. All the chemicals are weighed accurately using an electrical balance which are grounded to fine powder and mixed thoroughly. The batches are taken in silica crucibles and melted in an automatic temperature controlled electrical furnace in air at $1100^{\circ} \mathrm{C}$ about 20 minutes. The resultant bubble free transparent liquid is then poured on a brass mould and subsequently annealed to relieve the structural stress, about 24 hours at $350^{\circ} \mathrm{C}$. The glasses thus obtained are transparent and brown. After polishing, good quality glasses obtained have been used for optical measurements.

\subsection{Measurement}

By Archimedes principle, the density (d) of the glass samples is measured at room temperature using a sensitive micro balance with O-xylene (99.99\% pure) as the immersion liquid. Average molecular weight (M), various physical parameters such as manganese ion concentration $\left(\mathrm{N}_{\mathrm{i}}\right)$, mean manganese ion separation $\left(\mathrm{r}_{\mathrm{i}}\right)$, the polaron radius $\left(\mathrm{r}_{\mathrm{p}}\right)$ and optical basicity $\left(\Lambda^{\text {th }}\right)$ are evaluated.

$\mathrm{X}$-ray diffraction technique is employed to check for possible crystallinity of the samples after quenching and annealing. X-ray powder diffraction patterns of glass samples are recorded using copper target on Philips PW (1710) Diffractometer at room temperature. The optical absorption spectra of $\mathrm{MnO}_{2}$ doped NPAB glasses are recorded at room temperature in the wavelength range 200-1200 $\mathrm{nm}$ up to a resolution of $0.1 \mathrm{~nm}$ using JASCO model V-670 UVVIS-NIR spectrophotometer. Glass samples of thickness $1 \mathrm{~mm}$ are used for optical measurements. The Electron paramagnetic resonance spectra of fine powders of the samples have been recorded at room temperature on JEOL JES-FA200 EPR Spectrometer operating in the $\mathrm{X}$-band frequency $(\mathrm{v}=9.732 \mathrm{GHz})$ with a field modulation of $100 \mathrm{KHz}$. The magnetic field is scanned between 0 to 5000 Gauss with a scan speed of 250 Gauss per minute and the microwave power used is $5 \mathrm{~mW}$. A powdered glass specimen of $100 \mathrm{mg}$ has been taken in a quartz tube for EPR measurements. FT-IR spectra of various as prepared glass samples are obtained by Perkin Elmer 577 infrared Spectrometer to an accuracy of $0.1 \mathrm{~cm}^{-1}$ in the frequency range $4000-500 \mathrm{~cm}^{-1}$ using $\mathrm{KBr}$ pellets (300mg) containing pulverized sample $(1.5 \mathrm{mg})$. These pellets are pressed at a vacuum die at $\square 680 \mathrm{Mpa}$.

\section{Results}

\subsection{Powder X-ray diffraction (PXRD) study}


Fig. 1 shows the typical PXRD pattern of undoped and $\mathrm{MnO}_{2}$ doped NPAB glasses did not reveal any crystalline phase which asserts the amorphous nature.

\subsection{Physical parameters}

Based on the measured glass density (d) and calculated molecular weight (M), various physical parameters such as manganese ion concentration $\left(\mathrm{N}_{\mathrm{i}}\right)$, mean manganese ion separation $\left(r_{i}\right)$, Polaron radius $\left(r_{p}\right)$, and optical basicity $\left(\Lambda^{\text {th }}\right)$ are evaluated using conventional formulae [24] and the values obtained are presented in Table 2 .

\subsection{Electron Paramagnetic Resonance (EPR)}

Fig. 2 represents the typical EPR spectra of $\mathrm{MnO}_{2}$ doped NPAB glass samples. EPR signal is not detected in the spectra of undoped glass which indicate that there are no paramagnetic impurities in the starting materials. The EPR spectra of all Mn(II) doped NPAB glass systems at room temperature exhibit the standard hyperfine sextet (hfs) structure around $\mathrm{g}$ $=2.001$ which is a fundamental characteristic signal of $\mathrm{Mn}^{2+}$ ions. Each fine structure transition split into six hyperfine components due to the interaction of electron spin with the ${ }^{55} \mathrm{Mn}$ nucleus $(I=5 / 2)$. The significant data related to EPR spectra are listed in Table 3.

\subsection{Optical absorption studies}

The optical absorption spectra of $\mathrm{MnO}_{2}$ doped NPAB glass samples recorded in the wavelength region of 200-1200 $\mathrm{nm}$ are shown in the Fig. 3. The absorption edge occurred at a wavelength of $310 \mathrm{~nm}$ for pure NPAB glass. The absorption edge shifts towards higher wavelength with the doping of manganese ions. The optical absorption spectra of $\mathrm{MnO}_{2}$ doped NPAB glasses consist a broad absorption band in the visible region at $\square 21000 \mathrm{~cm}^{-1}$. This band is observed originated from ${ }^{6} \mathrm{~A}_{1 \mathrm{~g}}(\mathrm{~S}) \rightarrow{ }^{4} \mathrm{~T}_{1 \mathrm{~g}}(\mathrm{G})$ octahedral transition of $\mathrm{Mn}$ (II) ions belong to $\mathrm{d}^{5}$ configuration. The exact band positions for individual glasses studied are presented in Table 4. With an increase in the concentration of $\mathrm{MnO}_{2}$, the intensity of octahedral band is observed to grow gradually with minor red shift. The position of the bands is shifted slightly towards the lower frequency side with increasing concentration of $\mathrm{MnO}_{2}$.

The study of optical band gap in the amorphous materials is the subject of considerable research. This is related to the energy gap between valence and conduction bands [25]. In glasses, the study of optical absorption in the ultraviolet region is a useful method to understand 
the band structure. The conduction band is influenced by the glass forming anions, the cations also play an indirect but important role [25]. In general, there are two kinds of optical transitions at the fundamental edge of crystalline and non-crystalline semiconductors; direct and indirect transitions. In the direct optical transition from the valence band to the conduction band, it is essential that the wave vector for the electron be unchanged [26]. In case of the indirect transitions, interactions with lattice vibrations (phonons) takes place, thus the wave vector of the electron can change in the optical transition and the momentum change will be taken or given up by phonons. Plotting $(\alpha h v)^{1 / 2}$ as a function of hv suggested by Tauc [27] and discussed totally by Davis and Mott [28].

The absorption coefficient $\alpha(v)$ is given by [29]

$$
\alpha(v)=(1 / t) \ln \left(I / I_{0}\right)
$$

where $t$ is the thickness of the sample and $\ln \left(I / I_{0}\right)$ corresponds to absorbance factor.

The absorption coefficient $\alpha(v)$ can be related to optical band gaps of direct and indirect transitions following Davis and Mott [28].

$$
\alpha(v)=B\left(h v-E_{o p t}\right)^{n}
$$

where $\mathrm{B}$ is the energy-independent constant [30], $\mathrm{E}_{\mathrm{opt}}$ is the energy of the optical band gap and $\mathrm{h} v$ is the incident photon radiation. For indirect transitions $n=\frac{1}{2}$ and for direct transitions $n=2$.

The main feature of the absorption edge of an amorphous semiconductor is an exponential increase of the absorption coefficient with photon energy in accordance with an empirical relation given by Hassan and Hogarth [31]

$$
\alpha(v)=\alpha_{0} \exp (h v / \Delta E)
$$

where $\alpha_{0}$ is a constant and $\Delta \mathrm{E}$ is the Urbach energy which indicates the width of band tail of the localized states in the band gap.

The direct and indirect band gap energy values $\mathrm{E}_{\mathrm{opt}}$ can be obtained by extrapolating the absorption coefficient to zero absorption in $(\alpha h v)^{2}$ vs. $h v,(\alpha h v)^{1 / 2}$ vs. hv plot and is shown in Fig. 4 and 5. Plots have been also drawn between $\ln (\alpha)$ vs. hv (Fig. 6) and the Urbach energy values $(\Delta \mathrm{E})$ are calculated by taking the reciprocal of the slopes of linear portion in the lower photon energy region of the curve [32]. The optical band gaps for direct, indirect transitions and Urbach energies obtained in the present work are listed in Table 5.

\subsection{FT-IR study}


Fig. 7 represents FT-IR transmittance spectra of NPAB glasses at room temperature. The undoped and manganese doped NPAB glasses exhibited three groups of prominent bands. (i) The first group of bands are appeared at $1200-1600 \mathrm{~cm}^{-1}$, these are identified as symmetric stretching relaxations of $\mathrm{B}-\mathrm{O}$ bonds of the trigonal $\mathrm{BO}_{3}$ units. The second group of broad absorption bands are observed at $800-1200 \mathrm{~cm}^{-1}$; these are identified as $\mathrm{B}-\mathrm{O}$ asymmetric stretching vibrations of the tetrahedral $\mathrm{BO}_{4}$ units and the third group of bands are observed in between the region $600-800 \mathrm{~cm}^{-1}$ due to the bending of $\mathrm{B}-\mathrm{O}-\mathrm{B}$ linkages in the borate network [33]. The FT-IR band positions and their assignments are given in Table 6.

\section{Discussion}

\subsection{Powder X-ray diffraction (PXRD) study}

X-ray diffraction is a useful technique to detect the structural changes in any type of materials. The dimensions of glassy materials are greater than typically $100 \mathrm{~nm}$ [34]. The PXRD pattern exhibited a broad diffuse scattering at angle, which indicated a long-range structural disorder characteristic of vitreous solids. In glasses, the atoms are not regularly spaced and nonuniform as in the case of crystals. Due to the variations in inter atomic distances of glasses; the peaks get broader. Thus, the undoped and $\mathrm{MnO}_{2}$ doped NPAB glass samples are found to be completely amorphous in nature.

\subsection{Physical parameters}

The modification of the geometrical configuration, co-ordination number, cross-link density and dimensions of interstitial space may have influenced the density of the glass matrix. Therefore, density is a powerful physical parameter which reveals the degree of change in structure with change in composition of glasses. From Table 2, it is observed that density values are increased gradually with the content of $\mathrm{MnO}_{2}[35,36]$. Polaron radius $\left(\mathrm{r}_{\mathrm{p}}\right)$ values are found consistently less than that of inter ionic distance $\left(r_{i}\right)$ in all glasses. Further, the values of $r_{p}$ and $r_{i}$ gradually decreased with increasing concentration of $\mathrm{MnO}_{2}$.

\subsection{Electron Paramagnetic Resonance (EPR)}

The $g$ values obtained for $\mathrm{Mn}(\mathrm{II})$ ions in the present glass system is comparable with that of other glass systems, such as lead alumino borate glasses [1], soda lime silicate glasses [37] 
and alkali sulphate glasses [38]. For Mn(II) ion, if we neglect the nuclear Zeeman term, the spin Hamiltonian term can be written as

$$
\mathrm{H}=\mu_{\mathrm{B}} \mathrm{gBS}+\mathrm{ASI}+\mathrm{D}\left[\mathrm{S}_{\mathrm{Z}}^{2}-\left\{\frac{1}{3} \mathrm{~S}(\mathrm{~S}+1)\right\}\right]+\mathrm{E}\left(\mathrm{S}_{\mathrm{X}}^{2}-\mathrm{S}_{\mathrm{Y}}^{2}\right)
$$

where $\mu_{\mathrm{B}}$ is the Bohr magneton, $\mathrm{g}$ is the electronic $\mathrm{g}$ factor, $\mathrm{B}$ is the Zeeman field, $\mathrm{S}$ is the $\mathrm{Mn}^{2+}$ electronic spin=5/2, A is the hyperfine interaction tensor, $\mathrm{I}$ is the $\mathrm{Mn}(\mathrm{II})$ nuclear spin=5/2 and D and $\mathrm{E}$ are the non-axial zero field splitting parameters.

The hyperfine splitting constant ' $A$ ' can be calculated from the position of the allowed hyperfine lines using the formula:

$$
\mathrm{H}_{\mathrm{m}}=\mathrm{H}_{0} \square \mathrm{A}_{\mathrm{m}} \square\left(35 \square 4 \mathrm{~m}^{2}\right) \frac{A^{2}}{8 H_{0}}
$$

where $\mathrm{H}_{\mathrm{m}}$ is the magnetic field corresponding to $\mathrm{m} \leftrightarrow \mathrm{m}$ hyperfine line, $\mathrm{H}_{0}$ the resonance magnetic field. The $g$ and $A$ values have been calculated for all the glass samples under investigation. Within the experimental error, the $\mathrm{g}$ and $\mathrm{A}$ values are found to be independent of temperature, alkali size and manganese content.

In the case of $\mathrm{d}^{5}$ metal ions, it is familiar that the axial distortion of $\mathrm{Mn}$ (II) octahedral symmetry gives rise to three Kramer's doublets $\square \square \frac{5}{2} \square \square \square \frac{3}{2} \square \square \frac{1}{2}$ [39]. The EPR spectra exhibited only one prominent signal with six-line hyperfine structure (given by the isolated $\mathrm{Mn}^{2+}$ ions) with high intensity at $\mathrm{g}=2.0$ is observed. This multiplet is arises from the transition between the energy levels of the lower Kramer's doublet i.e. from $M_{s}=-\frac{1}{2} \square+\frac{1}{2}$, where $M_{s}$ is the effective electronic spin component. The population of these doublets produce splitting in EPR signal. From the Fig. 2 it is observed that the sextet lines in $g=2.00$ are not equally spaced and the separation between the hyperfine (hf) lines increases from low field side to high field side of the spectrum. The increase of the $\mathrm{MnO}_{2}$ content leads to increase in the line width of the sextet, which is due to the dipole-dipole interaction of the paramagnetic ions. Moreover, the sextet gradually tends to become a broad single line spectrum. The resolved hyperfine spectra around $\mathrm{g}$ $=2.00$ and the magnitude of hfs $(\mathrm{A})$ constant is $93 \times 10^{-4} \mathrm{~cm}^{-1}$ in the glass matrix are strongly indicate that the $\mathrm{Mn}$ (II) ions are present in octahedral symmetry [40]. According to Van Wieringen, there is a regular variation of hyperfine coupling constant(A) with covalence [41]. From the large hyperfine coupling constant values the ionic nature of bonding is high between 
Mn(II) ions and its ligands. The nature of bonding is successfully explained based on the hyperfine splitting g-value. If g-value shows a negative shift $\left(g<g_{e}\right)$ with respect to the free electron value ( $\left.g_{e}=2.0023\right)$, then the bonding is ionic and conversely, if the shift is positive ( $g$ > $\mathrm{g}_{\mathrm{e}}$ ), then the bonding is more covalent in nature. In the present work, the observed ' $\mathrm{g}$ ' value (2.0057) shows positive shift in $\mathrm{Mn}_{1}$ glass sample, indicates the less covalent nature. The ' $\mathrm{g}$ ' values (2.0010 1.9969$)$ show negative shift in all remaining glass samples, indicates the ionic nature. Hence, It is clear that the ionic character of $\mathrm{Mn}(\mathrm{II})$ ions in NPAB glasses gradually increases with increasing concentration of $\mathrm{MnO}_{2}$ [41].

\subsection{Optical absorption studies}

The optical basicity of an optical glass serves in the first approximation as a measure [42] of the ability of oxygen to donate a negative charge to the probe ion. Duffy and Ingram [43] reported that the ideal values of optical basicity can be calculated from the composition of the glass and the basicity moderating parameters of the various cations present.

Theoretical optical basicity values of the glass can be estimated using the following formula.

$$
\Lambda^{\text {th }}=\sum_{i=1}^{n} \frac{z_{i} r_{i}}{2 \gamma_{i}}
$$

where $n$ be the total number of cations present, $z_{i}$ is the oxidation number of the $i^{\text {th }}$ cation, $r_{i}$ is the ratio of number of $\mathrm{i}^{\text {th }}$ cations to the oxides present and $\gamma_{\mathrm{i}}$ is the basicity moderating parameter of the $i^{\text {th }}$ cation. The basicity moderating parameter $\gamma_{i}$ can be calculated from the following equation [42].

$$
\gamma_{i}=1.36\left(x_{i}-0.26\right)
$$

where $x_{i}$ is the Pauling's electro negativity [44] of the cation. Pauling's electro negativity of boron, lead, aluminum, sodium and manganese ions is $2.04,2.33,1.61,0.93 \& 1.55$ respectively. Theoretical values of optical basicity $\left(\Lambda^{\text {th }}\right)$ have been calculated and presented in Table 4 . In the present study from Table 4, it is observed that the optical basicity is increased indicates the covalence between manganese ions and oxygen ions decreased with increasing concentration of manganese ions.

Electronic configuration of $\mathrm{Mn}(\mathrm{II})$ ion is (Ar) $3 \mathrm{~d}^{5}$ corresponds to half-filled $\mathrm{d}$ orbital. This configuration gives ${ }^{6} \mathrm{~S},{ }^{4} \mathrm{P},{ }^{4} \mathrm{~F},{ }^{4} \mathrm{D},{ }^{4} \mathrm{G}$ free ion terms and in addition to a number of doublet states of which ${ }^{6} \mathrm{~S}$ occupies the ground state. In octahedral symmetry, ${ }^{6} \mathrm{~S}$ and ${ }^{4} \mathrm{P}$ transform as 
spherically non-degenerate ${ }^{6} \mathrm{~A}_{1 \mathrm{~g}}$ and ${ }^{4} \mathrm{~T}_{1 \mathrm{~g}},{ }^{4} \mathrm{~F}$ splits into ${ }^{4} \mathrm{~A}_{2 \mathrm{~g}}+{ }^{4} \mathrm{~T}_{2 \mathrm{~g}}+{ }^{4} \mathrm{~T}_{1 \mathrm{~g}},{ }^{4} \mathrm{D}$ splits into ${ }^{4} \mathrm{E}_{\mathrm{g}}+{ }^{4} \mathrm{~T}_{2 \mathrm{~g}}$ and ${ }^{4} \mathrm{G}$ splits into ${ }^{4} \mathrm{~A}_{1 \mathrm{~g}}+{ }^{4} \mathrm{E}_{\mathrm{g}}+{ }^{4} \mathrm{~T}_{1 \mathrm{~g}}+\mathrm{T}_{2 \mathrm{~g}}$ respectively.

Generally, manganese ions can exist in different oxidation states such as divalent $\left(\mathrm{Mn}^{2+}\right)$ ions [1], trivalent $\left(\mathrm{Mn}^{3+}\right)$ ions [45] and also tetravalent $\left(\mathrm{Mn}^{4+}\right)$ ions [46] in lead oxide glasses. In the optical absorption spectra of $\mathrm{MnO}_{2}$ doped NPAB glasses, a broad band appeared near 21000 $\mathrm{cm}^{-1}$ is assigned to ${ }^{6} \mathrm{~A}_{1 \mathrm{~g}}(\mathrm{~S}) \rightarrow{ }^{4} \mathrm{~T}_{1 \mathrm{~g}}(\mathrm{G})$ transition, indicates that the characteristic absorption of distorted octahedral site symmetry of Mn(II) ions [47]. The increasing value of absorption edge with increasing $\mathrm{MnO}_{2}$ concentration also supports that manganese ions are predominantly in octahedral Mn(II) state which occupy network modifier positions. The gradual increase in the half width and intensity of octahedral band suggests that there is a growing concentration of $\mathrm{Mn}$ (II) ions in the glass network with increasing content of $\mathrm{MnO}_{2}$.

From Table 5, it is noticed that direct, indirect optical band gap energy values are decreased and Urbach energy values are increased with increasing concentration of $\mathrm{MnO}_{2}$. The decrease in the band gap may be explained as follows. The decrease in the band gap causes the increase in non-bridging oxygen (NBOs) in the glass matrix. This leads to increasing degree of localization of electrons thereby increase in the number of donor centers in the glass matrix. The presence of large concentration of these donor centers lowers the optical band gap and shifts the absorption edge towards lower energy side as observed. This suggests that growing concentration of $\mathrm{Mn}(\mathrm{II})$ ions are present in NPAB glasses. Increase in Urbach energy with $\mathrm{MnO}_{2}$ concentration confirms that the number of defects increase with Mn content. In the present study, the optical band gap values for direct transitions of the samples are exist in between 3.628 and $3.829 \mathrm{eV}$ and also in between 3.335 and $3.516 \mathrm{eV}$ for indirect transitions. The Urbach energy values are varying in between 0.304 and $0.340 \mathrm{eV}$ by increasing $\mathrm{MnO}_{2}$ content in glass compositions. The lowest band gap is observed in glass $\mathrm{Mn}_{5}$ and the highest band gap is observed in glass $\mathrm{Mn}_{1}$ for direct, indirect transitions. It is obvious from Table 4 that the least Urbach energy suggests that the glass stability is more in $\mathrm{Mn}_{1}$ sample compare to remaining glass samples. From the optical absorption data, it is noticed that the absorption band intensity increases with increase in the host glass basicity. This suggests that the ionic character increases with increasing $\mathrm{MnO}_{2}$ content. Similar observations are reported in earlier literature for borate glasses [48]. 
A plot is drawn between optical band gap energy and Urbach energy as a function of $\mathrm{MnO}_{2}$ content and is shown in Fig. 8. From this figure it is noticed that the band gap energy and Urbach energy for these NPAB glasses are existed in opposing manner.

\subsection{FT-IR study}

FT-IR spectroscopy is recognized to provide insights into the interaction between alkali metal ions and borate glass network. Boron has smallest mass as compared to other network forming elements, thus the major vibrational modes associated with the glass network resolve well above $500 \mathrm{~cm}^{-1}$ [49]. From the FT-IR spectra, one can clearly identify three broad and intense absorption bands centered around 1332, 1050 and $769 \mathrm{~cm}^{-1}$ have been observed in $\mathrm{Mn}_{0}$ sample. However, some shoulders and feeble bands located at 1246 and $697 \mathrm{~cm}^{-1}$ are found. The broad band at $1332 \mathrm{~cm}^{-1}$ and its shoulder at $1246 \mathrm{~cm}^{-1}$ are attributed to symmetric stretching relaxations of $\mathrm{B}-\mathrm{O}$ bonds of the trigonal $\mathrm{BO}_{3}$ units, whereas the band at $1050 \mathrm{~cm}^{-1}$ is identified due to asymmetric $\mathrm{B}-\mathrm{O}$ stretching vibrations of $\mathrm{BO}_{4}$ units [50]. The absorption band found at $769 \mathrm{~cm}^{-1}$ is due to $\mathrm{B}-\mathrm{O}-\mathrm{B}$ bending vibrations in the borate network, the feeble band at $697 \mathrm{~cm}^{-1}$ is due to $\mathrm{B}-\mathrm{O}-\mathrm{B}$ linkages. Boron is a network forming cation it may occupy the centers of oxygen triangles or tetragonal sites [51]. Besides the borate fundamental groups, this spectra also reveal a group of prominent absorption bands in the near infrared range from $2200-3200 \mathrm{~cm}^{-1}$ due to hydroxyl or water groups, these bands are persistent in all compositions [52]. However with increase in the content of $\mathrm{MnO}_{2}$ it is observed that the position of the bands due to $\mathrm{BO}_{3}$, $\mathrm{BO}_{4}$ and $\mathrm{B}-\mathrm{O}-\mathrm{B}$ units are shifted slightly towards the higher frequencies. The shifting of band positions in the IR spectra is observed as the concentration of manganese ions increased.

\section{Conclusions}

Density values are increased and $r_{p}, r_{i}$ values are decreased gradually with the content of $\mathrm{MnO}_{2}$. From the powder X-ray diffraction patterns, the prepared glass samples are amorphous in nature. EPR and optical absorption spectral data revealed that the doped Mn(II) ions are occupied at octahedral site symmetry in the host lattice. Increasing values of optical basicity and negative g- shift strongly confirm that $\mathrm{Mn}(\mathrm{II})$ - ligand bonds are more ionic in nature. FT-IR spectral analysis confirms the presence of network structural $\mathrm{BO}_{3}, \mathrm{BO}_{4}$ and $\mathrm{B}-\mathrm{O}-\mathrm{B}$ groups in all glass systems.

\section{Acknowledgements}


The authors are thankful to the UGC - DST-FIST, New Delhi for sanctioning equipment to the Department of Physics, Acharya Nagarjuna University to carry out the present research work.

\section{References}

[1] M. Sathish, B. Eraiah Inter. "Synthesis, Characterization and Optical Properties of Niobium Doped Silver-Lead-Borate Glasses”, J. Engg. Res. and Appl. 2, 1264-1270 (2012).

[2] Y.D. Siva Prasad, A. Veerabhadra Rao, K. Srikanth and K.A. Emmanuel, "Spectroscopic and magnetic properties as probe in the structural study of pbo-zno-b2o3 glass system doped with mnO”, Rasayan J. chem. 4, 358-370 (2011).

[3] N.C.A. deSousa, M.T. deAraujo , C. Jacinto , M.V.D. Vermelho , N.O. Dantas , C.C. Santos, I. Guedes, "The role of $\mathrm{TiO}_{2}$ in the $\mathrm{B}_{2} \mathrm{O}_{3}-\mathrm{Na}_{2} \mathrm{O}-\mathrm{PbO}-\mathrm{Al}_{2} \mathrm{O}_{3}$ glass system", J. Solid State Chem. 184, 3062-3065 (2011).

[4] P. Venkat Reddy, C. Laxmi Kanth, V. Prashanth Kumar, N. Veeraiah, P. Kistaiah, "EPR and optical properties of alkali halo cadmium borate glasses containing vanadium ions", J. Non-Cryst. Solids 351, 3752-3759 (2005).

[5] J. Mauro, Glass Laboratory, College of Ceramics, Alfred University. (Private communication through the Internet) (2000).

[6] M. Yasuoka, K. Hirao, M.E. Brito, S. Kanzaki, "High- Strength and High- FractureToughness Ceramics in the $\mathrm{Al}_{2} \mathrm{O}_{3} / \mathrm{LaAl}_{11} \mathrm{O}_{18}$ Systems”, J. Am. Ceram. Soc. 78, 1853-1856 (1995).

[7] B.K. Jang, T. Kishi, "Fabrication and Microstructure of A12O3 Matrix Composites by Insitu Reaction in the $\mathrm{Al}_{2} \mathrm{O}_{3}-\mathrm{La}_{2} \mathrm{O}_{3}$ System", J. Ceram. Soc. Jpn. 106, 739-743 (1998).

[8] C. Barrera Solano, L. Esquivias, G.L. Messing, "Effect of Preparation Conditions on Phase Formation, Densification, and Microstructure Evolution in La- $\beta$ $\mathrm{Al}_{2} \mathrm{O}_{3} / \mathrm{Al}_{2} \mathrm{O}_{3}$ Composites", J. Am. Ceram. Soc. 82, 1318-1324 (1999).

[9] C.K. Narula, J.E. Allison, D.R. Bauer, H.S. Gandhi, "Materials Chemistry Issues Related to Advanced Materials Applications in the Automotive Industry”, Chem. Mater. 8, 9841003 (1996). 
[10] James F Shackelford, Robert H Doremus, , Ceramic and Glass Materials: Structure, Properties and Processing, Springer, 2008.

[11] G. Cormier, J.A. Capobianco, A. Monteil, "Molecular dynamics simulation of lead metaphosphate $\mathrm{Pb}\left(\mathrm{PO}_{3}\right)_{2}$ glass", J. Non-Cryst. Solids 168, 115-124 (1994).

[12] M.D. Ingram, "Ionic Conductivity in Glasses", Phys. Chem. Glasses 28, 215-234 (1987).

[13] S. Music, M. Gotic, S. Popovic, K. Furic and V. Mohacek, "Structural-Properties of Lead Vanadate Glasses Containing $\mathrm{La}^{3+}$ Or Fe ${ }^{3+}$ Ions", J. Mater. Sci. 29, 1227-1232 (1994).

[14] B. Vaidhyanathan, S. Asokan, K.J. Rao, J. Mater. Res. 15, 518-529 (2000).

[15] M. Ramireddy, G. Nagaraju, N. Veeraiah Indian J Engg. Mater. Sci. 13, 426-434 (2006).

[16] N.J. Kreidl, Recent applications of glass science, J. Non-Cryst. Solids 123, 377-384 (1990).

[17] J.C.Z.Nardi, Characterization of the $\mathrm{Li} / \mathrm{MnO}_{2}$ Multistep Discharge, J. Electrochem. Soc. 132, 1787-1791 (1985).

[18] L. Sanchez, J. Faray, J.P. Pereira - Ramos, L. Hernan, J. Morales, L. Tirado, "Lowtemperature mixed spinel oxides as lithium insertion compounds", J. Mater. Chem. 6, 37-39 (1996).

[19] R. N. Reddy, R.G. Reddy, "Synthesis and electrochemical characterization of amorphous $\mathrm{MnO}_{2}$ electrochemical capacitor electrode material”, J. Power Sourc. 132, 315-320 (2004).

[20] C-N Xu, K. Miyazaki, T. Watanable, "Humidity sensors using manganese oxides", Sens. Actu. B 46, 87-96 (1998).

[21] K. J. Kim, Y. R. Park. "Sol-gel growth and structural and optical investigation of manganese-oxide thin films: structural transformation by Zn doping”, J. Cryst. Growth 270, 162-167 (2004).

[22] G. Krishna Kumari, Ch. Rama Krishna, Sk. Muntaz Begum, V. Pushpa Manjari, P.N. Murthy, R.V.S.S.N. Ravikumar, "Mixed alkali effect in $\mathrm{Mn}^{2+}$ doped $20 \mathrm{ZnO}+\mathrm{xLi}_{2} \mathrm{O}+(30-\mathrm{x}) \mathrm{K}_{2} \mathrm{O}+50 \mathrm{~B}_{2} \mathrm{O}_{3}(5 \leqslant \mathrm{x} \leqslant 25)$ glasses", Spectrochim. Acta Part A: Mol. Bio. Spect. 101, 140-147 (2013).

[23] S. Sreehari Sastry, S. Vedavyas, B. Rupa Venkateswara Rao, "Influence of Various Glass Compositions on Physical and Spectroscopic Properties of Cao- $\mathrm{Pb}_{3} \mathrm{O}_{4}-\mathrm{Zno}-\mathrm{P}_{2} \mathrm{O}_{5}$ Glass System”, Inter. J. Innov. Res. in Sci., Engg. and Tech. 3(4) (2014). 
[24] Akiyoshi Osaka, Yu-hu Wang, Masanori Kobayashi, Yoshinari Miura, Katsuaki Takahashi, "Packing of atoms in lead halo silicate glasses of low silica content", J. NonCryst. Solids 105 (1988) 63-68.

[25] G. Fuxi, Optical and Spectroscopic Properties of Glasses, (Springer, Berlin, 1992), p. 62.

[26] M. Altaf, M.A. Chaudry, M. Zahid, "Study of Optical Band Gap of Zinc-Borate Glasses", J. Res. Sci. 14 (2), 253-259 (2003).

[27] J. Tauc, “Amorphous and Liquid Semiconductor”, (plenum, New York, 1974).

[28] N.F. Mott, E.A. Davis, Electronic Processes in Non-Crystalline Materials, 2nd edn., (Oxford University Press, Oxford, 1979), p. 273.

[29] R.H. Sands, Paramagnetic Resonance Absorption in Glass, Phys. Rev. 99, 1222-1226 (1995).

[30] S. Sindhu, A. Sanghi, A. Agarwal, V.P. Seth, N. Kishor, "Structural, optical, physical and electrical properties of $\mathrm{V}_{2} \mathrm{O}_{5}-\mathrm{SrO}-\mathrm{B}_{2} \mathrm{O}_{3}$ glasses", Spectrochim. Acta, Part A. 64, 196-204 (2006).

[31] M.A. Hassan, C.A. Hogarth, "A study of the structural, electrical and optical properties of copper tellurium oxide glasses”, J. Mater. Sci. 23, 2500-2504 (1988).

[32] Zhiwei Luo, Anxian Lu, "Thermal properties and optical band gap of a novel high UVtransmitting glass", Opto elec. Adv. Mater. Rap. Com., 6, 993-996 (2012), P.

[33] K. El-Egili, "Infrared studies of $\mathrm{Na}_{2} \mathrm{O}-\mathrm{B}_{2} \mathrm{O}_{3}-\mathrm{SiO}_{2}$ and $\mathrm{Al}_{2} \mathrm{O}_{3}-\mathrm{Na}_{2} \mathrm{O}-\mathrm{B}_{2} \mathrm{O}_{3}-\mathrm{SiO}_{2}$ glasses", Physica B 325, 340-348 (2003).

[34] G.W. Anderson, W.D. Luehrs, "Structural Characterization of and Phase Separation in Vanadate Glasses", J. Appl. Phys. 39, 1634-1638 (1968).

[35] Ch. Srinivasa Rao, V. Ravikumar, T. Srikumar, Y. Gandhi, N. Veeraiah, "The role of coordination and valance states of tungsten ions on some physical properties of $\mathrm{Li}_{2} \mathrm{O}-$ $\mathrm{Al}_{2} \mathrm{O}_{3}-\mathrm{ZrO}_{2}-\mathrm{SiO}_{2}$ glass system", J. Non-Cryst. Solids 357, 3094-3102 (2011).

[36] G. Little Flower, G. Sahaya Baskaran, N. Krishna Mohan, N. Veeraiah, "The structural role of tungsten ions in $\mathrm{PbO}-\mathrm{Sb}_{2} \mathrm{O}_{3}-\mathrm{As}_{2} \mathrm{O}_{3}$ glass-system by means of spectroscopic investigations", Mater. Chem. Phys. 100, 211-216 (2006). 
[37] Nattapon Srisittipokakun, Chittra KedKaew, Jakrapong Kaewkhao, Treedej Kittiauchawal, Kheamrutai Thamaphat and Pichet Limsuwan Kasetsart, "Electron Spin Resonance (ESR) and Optical Absorption Spectra of a Manganese Doped Soda-Lime-Silicate Glass System", J. Nat. Sci. 43, 360-364 (2009).

[38] A. S. Rao, B. Sreedher, and J. L. Rao, "Electron paramagnetic resonance and optical absorption spectra of $\mathrm{Mn}^{2+}$ ions in alkali zinc borosulphate glasses", J. Non-Cryst. Solids 144, 169-174 (1992).

[39] A. Abragam and B. Bleaney, Electron Paramagnetic Resonance of Transition Ions, (Clarendon Press, Oxford, (1970).

[40] H.B. Premkumar, D.V. Sunitha, H. Nagabhushana, S.C. Sharma, B.M. Nagabhushana, C. Shivakumara, J.L. Rao, R.P.S. Chakradhar, "Synthesis, characterization, EPR, photo and thermoluminescence properties of $\mathrm{YAlO}_{3}: \mathrm{Ni}^{2+}$ nanophosphors", J. Lumin. 135, 105-112 (2013).

[41] J.S. Van Wieringen, "Paramagnetic resonance of divalent manganese incorporated in various lattices", Discuss. Faraday Soc. 19, 118-126 (1955).

[42] V.P. Seth, S. Gupta, A. Jindal, S.K. Gupta, "ESR of vanadyl ions in $\mathrm{Li}_{2} \mathrm{O}-\mathrm{BaO}-$ $\mathrm{B}_{2} \mathrm{O}_{3}$ glasses," J. Non-Cryst. Solids 162, 263-267 (1993).

[43] J.A. Duffy, M.D. Ingram, Optical basicity-IV: "Influence of electronegativity on the Lewis basicity and solvent properties of molten oxyanion salts and glasses", Inorg. Nucl. Chem. 37, 1203-1206 (1975).

[44] L. Pauling, The Nature of Chemical Bond, 3rd edn., (Cornell University press, NewYork, 1960), p. 93.

[45] G. Lakshminarayana, S. Buddhudu, "Spectral analysis of $\mathrm{Mn}^{2+}, \mathrm{Co}^{2+}$ and $\mathrm{Ni}^{2+}: \mathrm{B}_{2} \mathrm{O}_{3}-\mathrm{ZnO}-$ PbO glasses", Spectrochim. Acta A 63, 295-304 (2006).

[46] N.W. Barnett, B.J. Hindson, P. Jones, A.S. Trevor, "Chemically induced phosphorescence from manganese (II) during the oxidation of various compounds by manganese (III), (IV) and (VII) in acidic aqueous solutions", Anal. Chim. Acta 451, 181-188 (2002).

[47] R.P. Sreekanth Chakradhar, B. Yasoda, J.L. Rao, N.O. Gopal, EPR and "Optical Studies of $\mathrm{Mn} 2+$ ions in Li2O-Na2O-B2O3 Glasses-An Evidence of Mixed Alkali Effect”, J. NonCryst. Solids 353, 2355-2362 (2007). 
[48] A. Murali, J.L. Rao, "Spectroscopic investigations on $\mathrm{Cu}(\mathrm{II})$ ions doped in alkali lead borotellurite glasses", J. Phys. Condens. Matter 11, $7921-7935$ (1999).

[49] A.J. Karki, S. Feller, H.P. Lim, J. Stark, C. Sanchez, M.J. Shibata, "The Density of SodiumBorate Glasses Related to Atomic Arrangements”, J. Non-Cryst. Solids 92, 11-19 (1987).

[50] C.P.E. Varsamis, E.I. Kamitsos, T. Minami, "Structural investigation of superionic AgIcontaining orthoborate glasses", J. Non-Cryst. Solids 345\&346, 93-98 (2004).

[51] Y. Cheng, H. Xiao, G. Wenming, G. Weiming, "Structure and crystallization kinetics of $\mathrm{Bi}_{2} \mathrm{O}_{3}-\mathrm{B}_{2} \mathrm{O}_{3}$ glasses", Thermochim. Acta 444, 173-178 (2006).

[52] G. El-Damrawi, K. El-Egili, "Characterization of novel $\mathrm{CeO}_{2}-\mathrm{B}_{2} \mathrm{O}_{3}$ glasses, structure and properties", Physica B 299, 180-186 (2001).

[53] Khalifa F A, Batal H a El \& Azooz A "Infrared absorption spectra of gamma irradiated glasses of the system $\mathrm{Li}_{2} \mathrm{O}-\mathrm{B}_{2} \mathrm{O}_{3}-\mathrm{Al}_{2} \mathrm{O}_{3}$ ”, Indian J Pure Appl. Phys. 36, 314-318 (1998). 
Figures

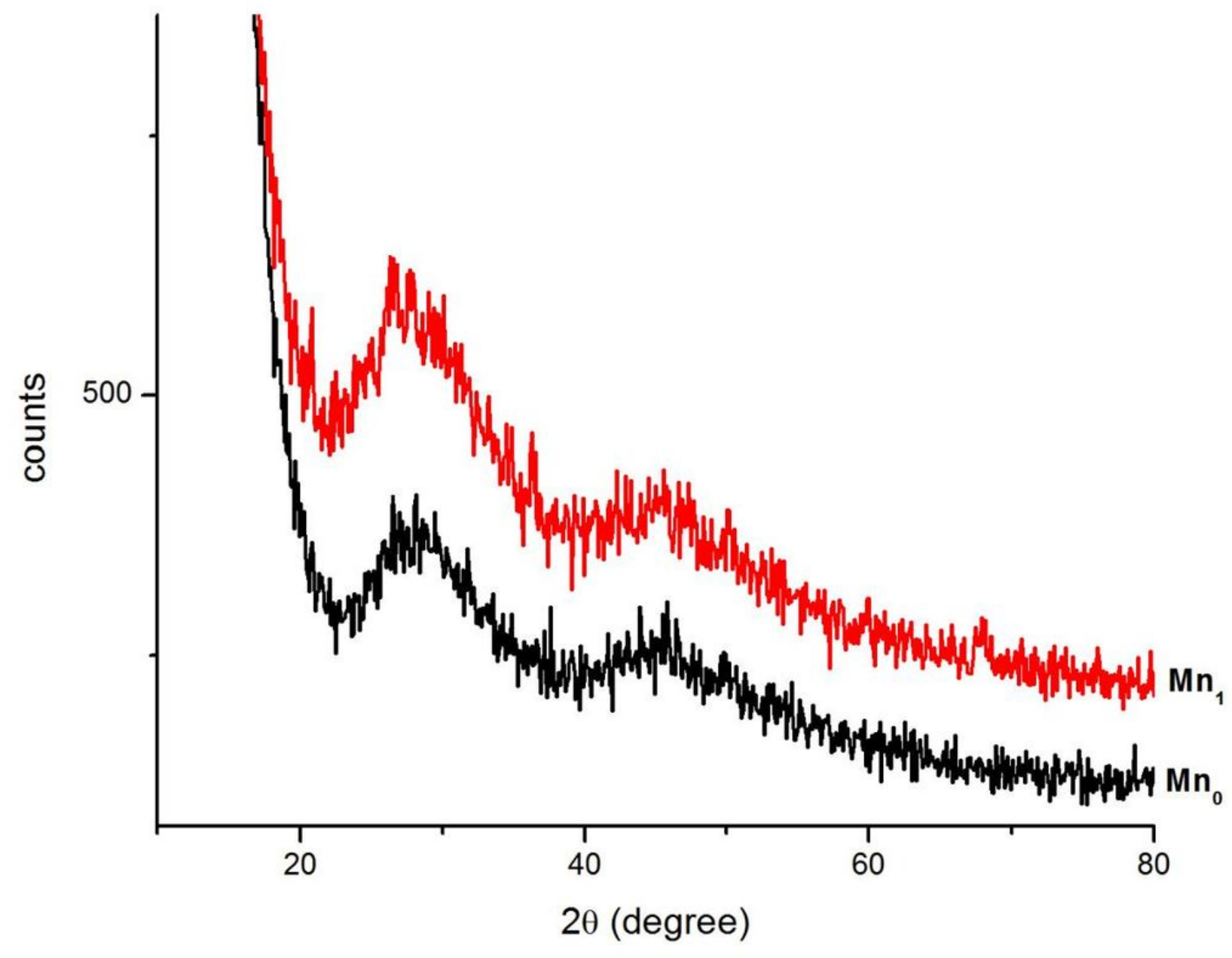

Figure 1

X-ray diffraction patterns of $\mathrm{MnO} 2$ doped NPAB glasses 


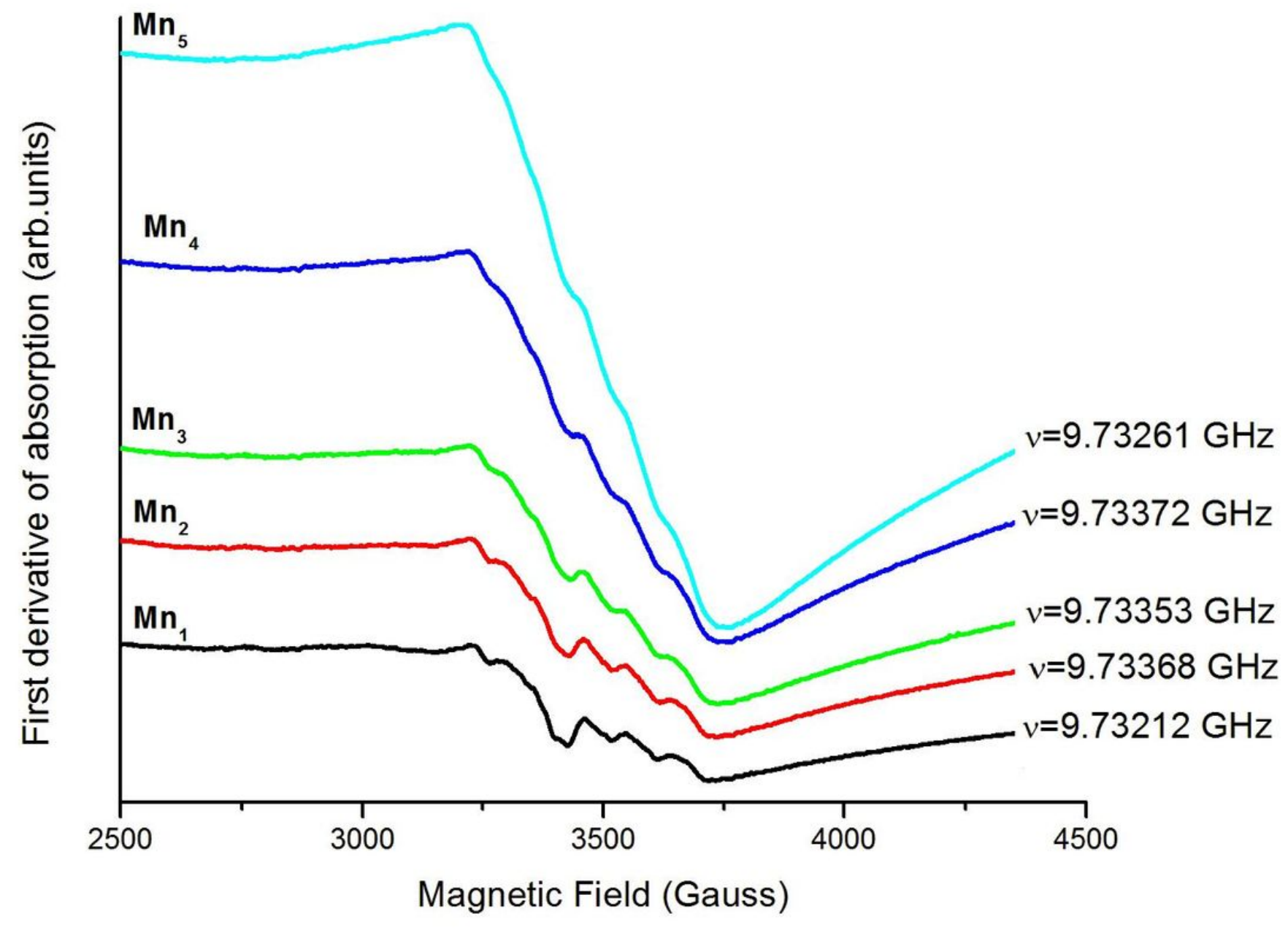

Figure 2

EPR spectra of $\mathrm{MnO} 2$ doped NPAB glasses 


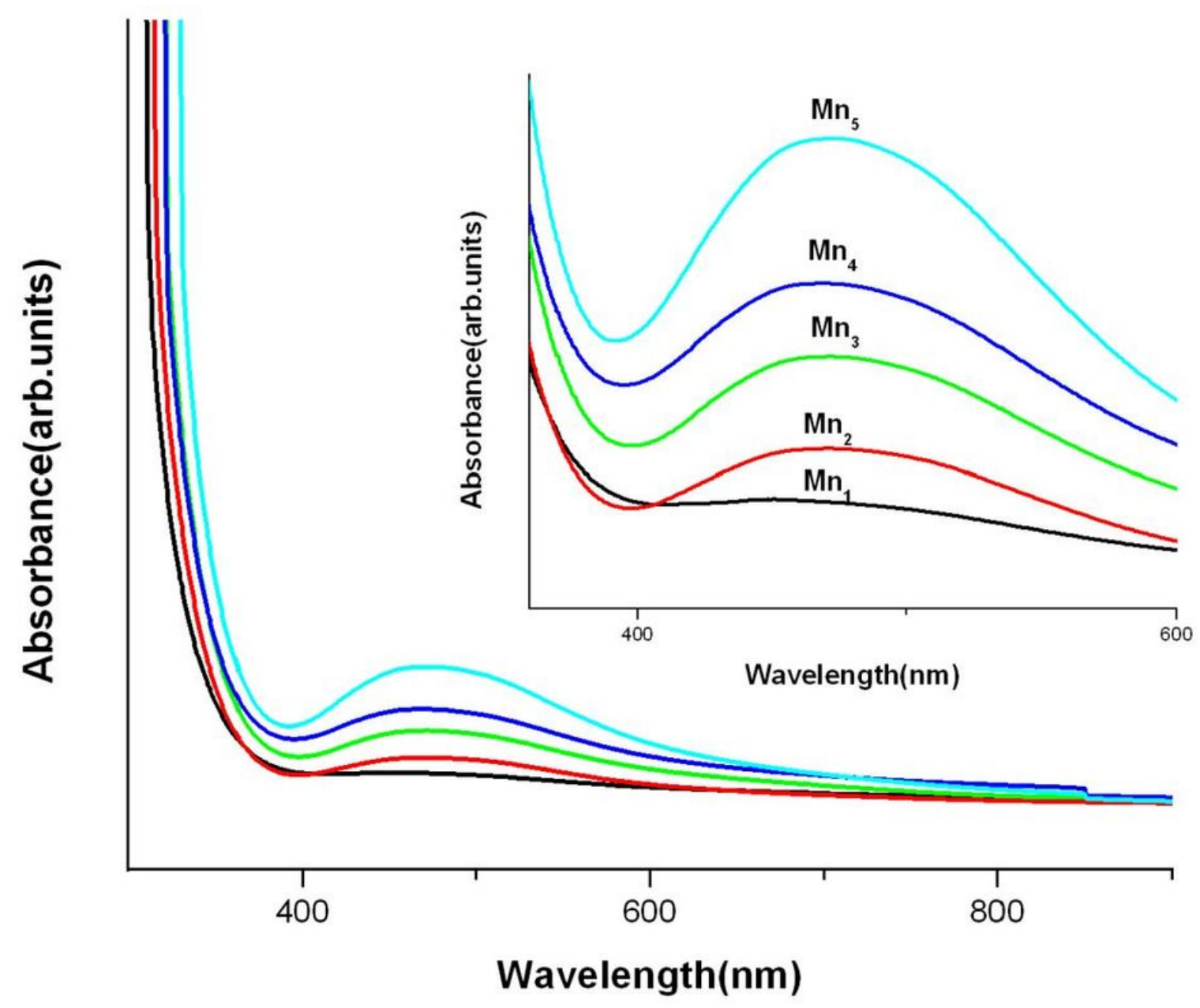

Figure 3

Optical absorption spectra of $\mathrm{MnO} 2$ doped NPAB glasses 


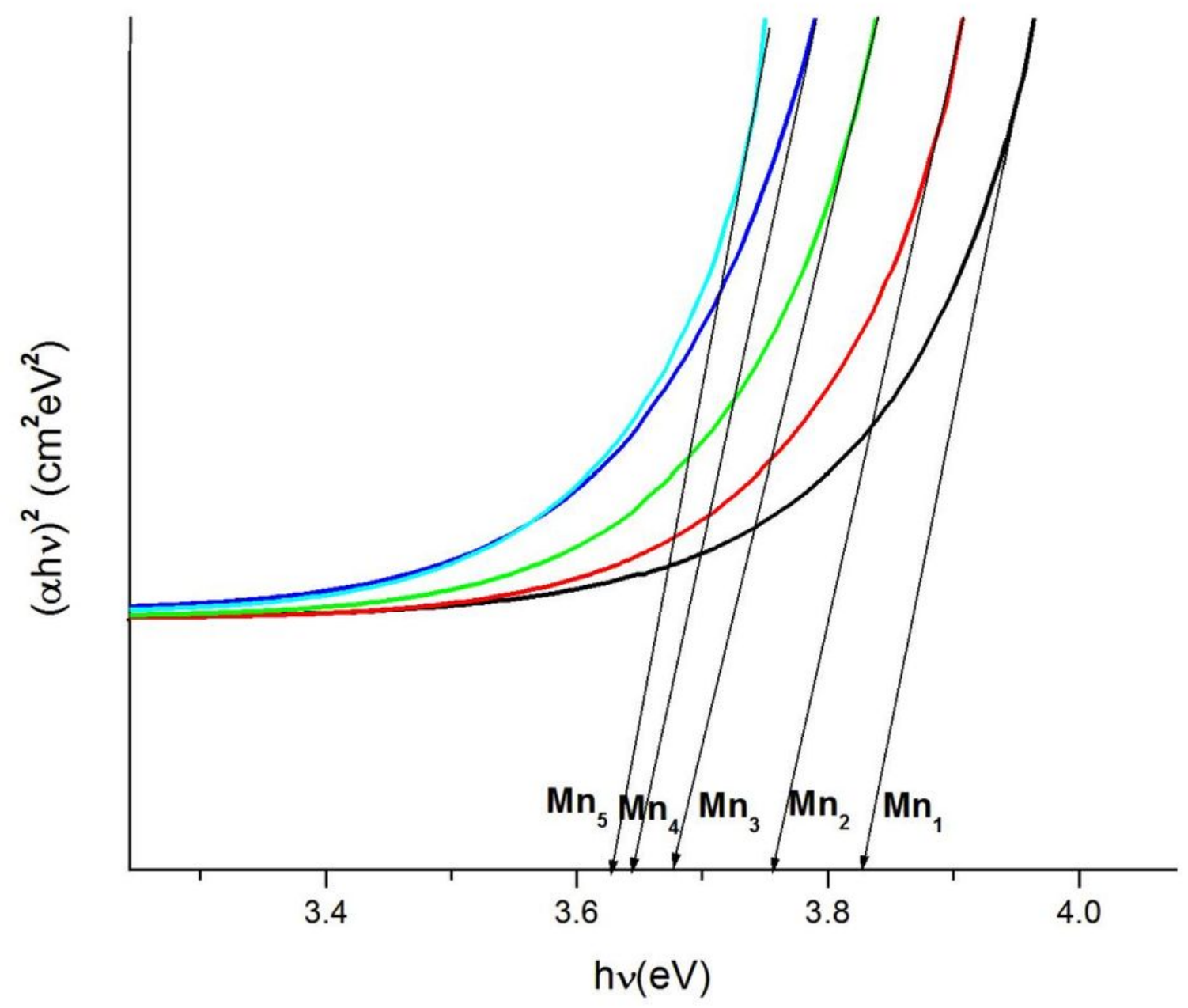

Figure 4

Direct bands of MnO2doped NPAB glasses 


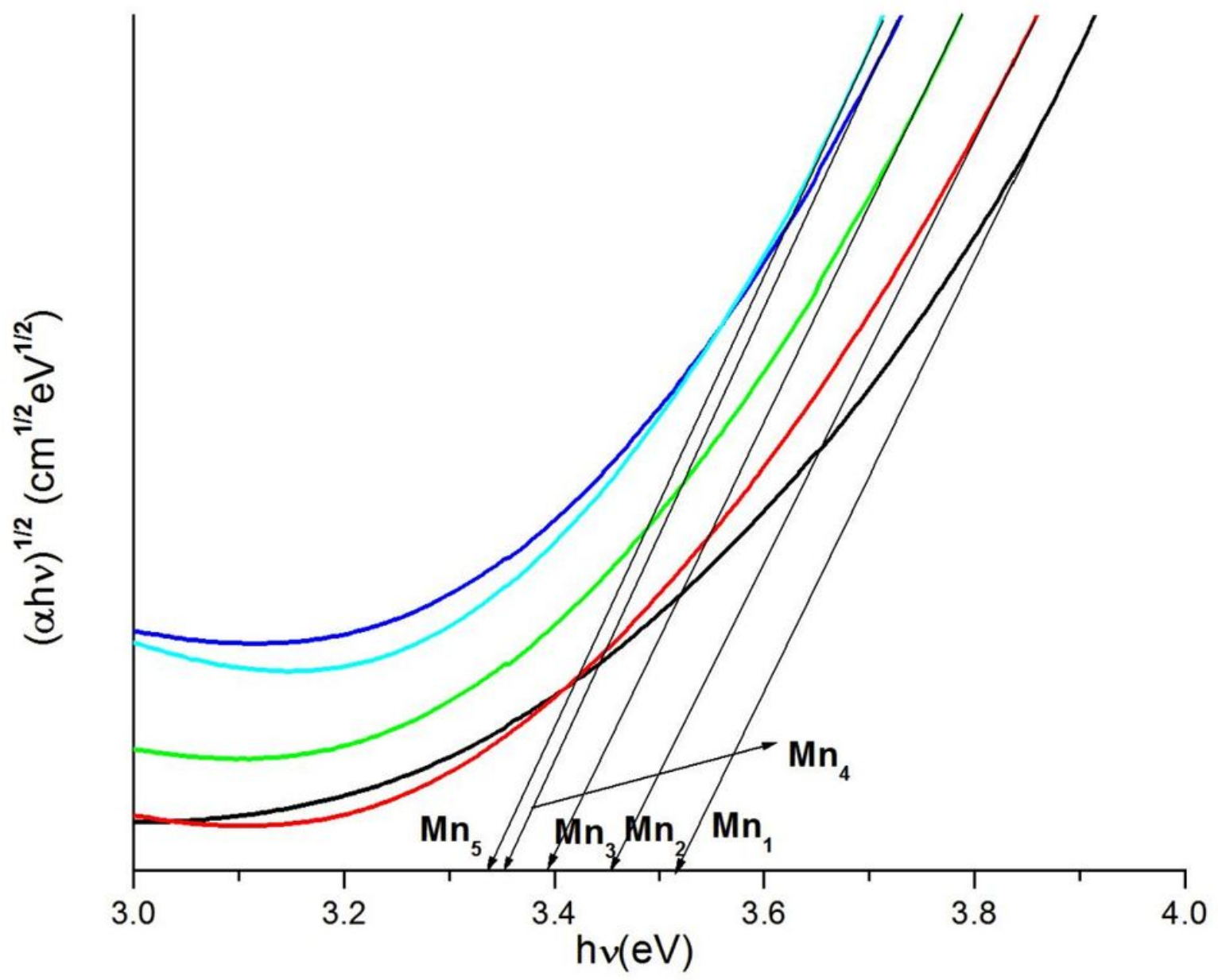

Figure 5

Indirect bands of $\mathrm{MnO} 2$ doped NPAB glasses 


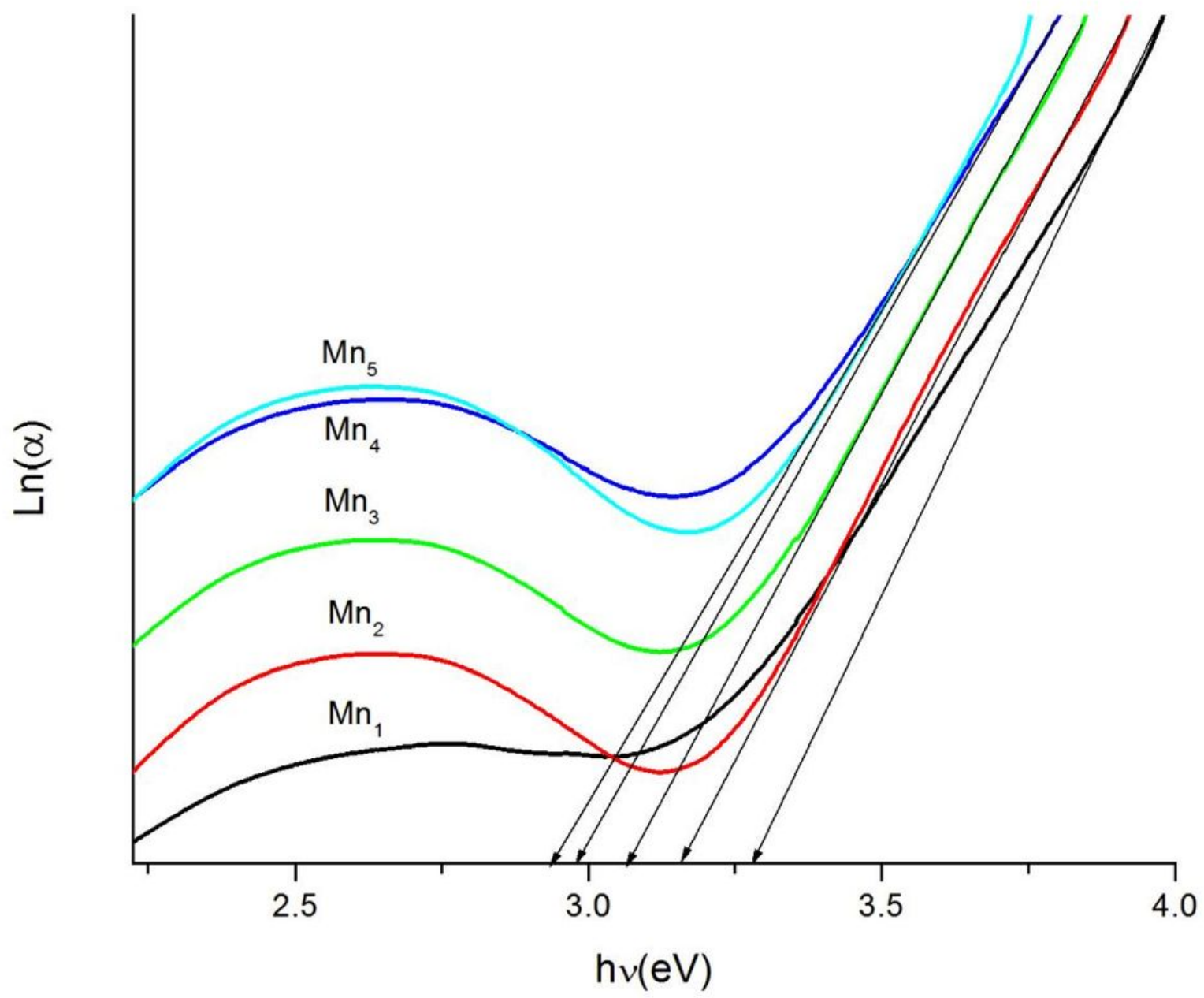

Figure 6

Urbach plots of $\mathrm{MnO} 2$ doped NPAB glasses 


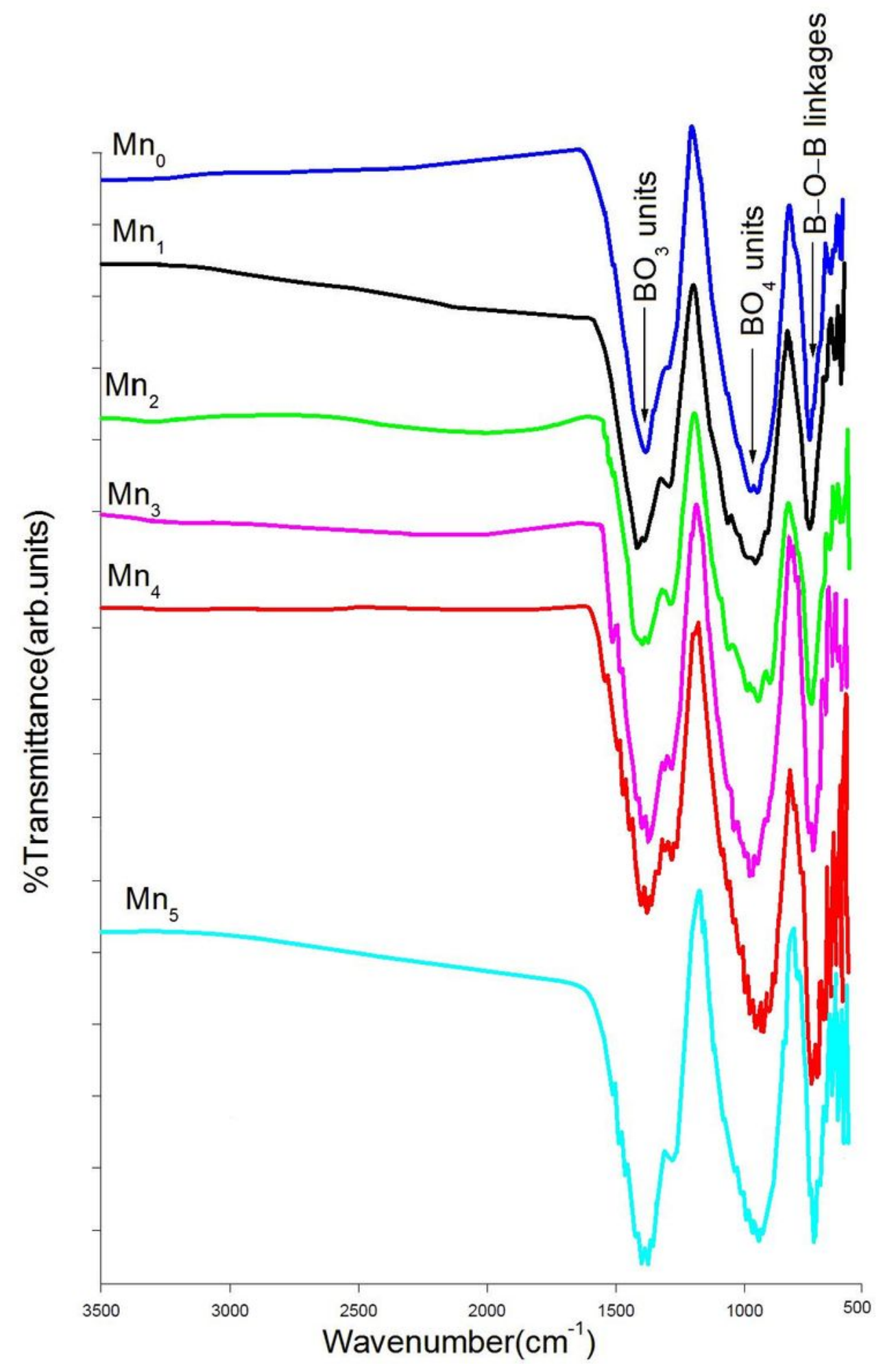

Figure 7

FT-IR spectra of MnO2 doped NPAB glasses 


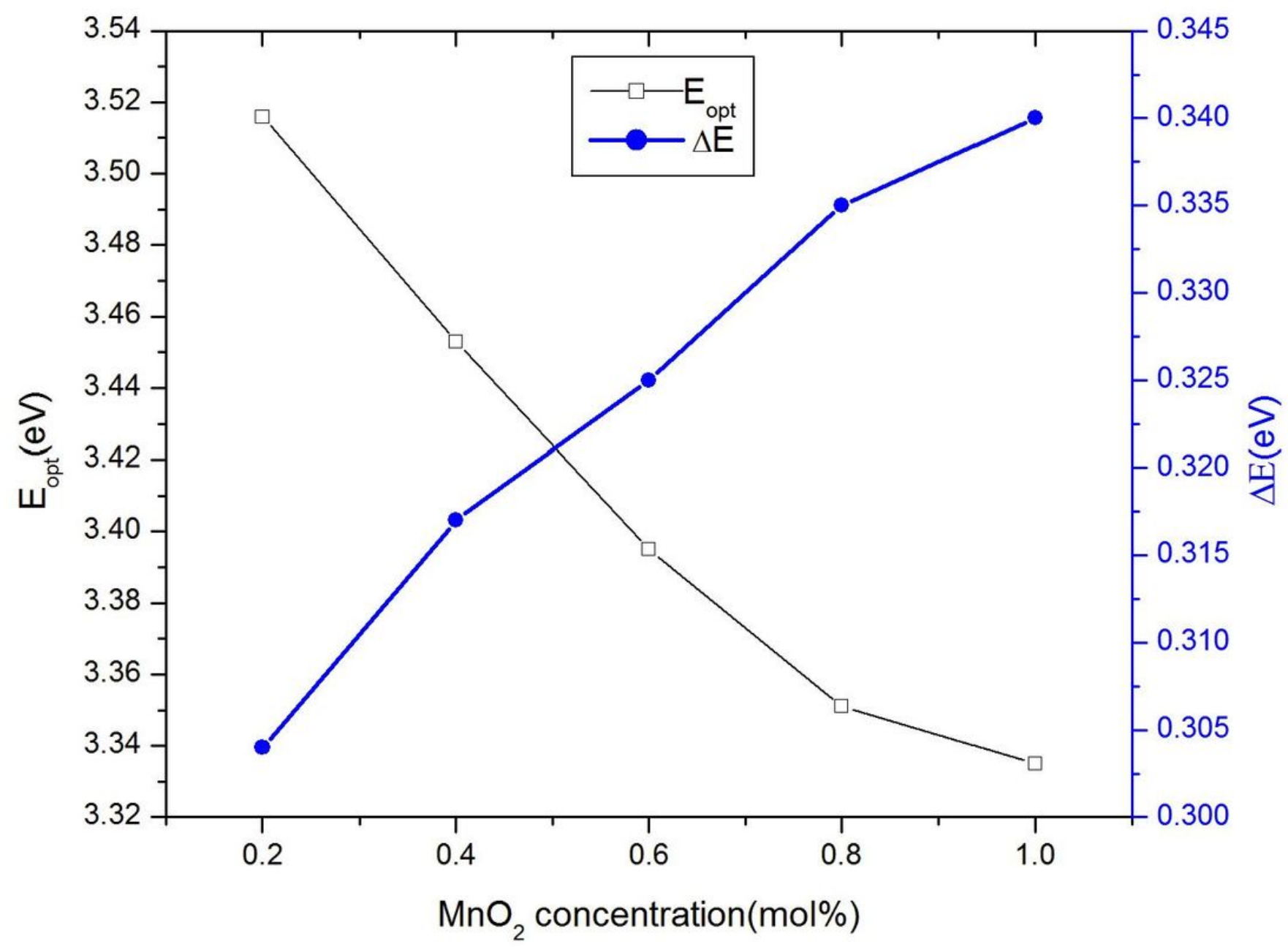

Figure 8

A plot of optical band gap (Eopt) and Urbach $(\Delta \mathrm{E})$ energies vs concentration of $\mathrm{MnO} 2$ in NPAB glasses

\section{Supplementary Files}

This is a list of supplementary files associated with this preprint. Click to download.

- GRAPHICALABSTRACT.docx 